\title{
Strain accumulation and fatigue crack initiation at pores and carbides in a SX superalloy at room temperature
}

DOI:

10.1016/j.jfatigue.2018.05.003

\section{Document Version}

Accepted author manuscript

Link to publication record in Manchester Research Explorer

\section{Citation for published version (APA):}

Jiang, R., Bull, D. J., Evangelou, A., Harte, A., Pierron, F., Sinclair, I., Preuss, M., Hu, X. T., \& Reed, P. A. S. (2018). Strain accumulation and fatigue crack initiation at pores and carbides in a SX superalloy at room temperature. International Journal of Fatigue, 114, 22-33. https://doi.org/10.1016/j.ijfatigue.2018.05.003

\section{Published in:}

International Journal of Fatigue

\section{Citing this paper}

Please note that where the full-text provided on Manchester Research Explorer is the Author Accepted Manuscript or Proof version this may differ from the final Published version. If citing, it is advised that you check and use the publisher's definitive version.

\section{General rights}

Copyright and moral rights for the publications made accessible in the Research Explorer are retained by the authors and/or other copyright owners and it is a condition of accessing publications that users recognise and abide by the legal requirements associated with these rights.

\section{Takedown policy}

If you believe that this document breaches copyright please refer to the University of Manchester's Takedown Procedures [http://man.ac.uk/04Y6Bo] or contact uml.scholarlycommunications@manchester.ac.uk providing relevant details, so we can investigate your claim.

\section{OPEN ACCESS}


Strain accumulation and fatigue crack initiation at pores and carbides in a SX superalloy at room temperature

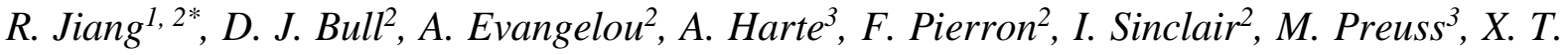 \\ $H u^{1}$, P.A.S. Reed ${ }^{2}$
}

1 College of Energy and Power Engineering, Nanjing University of Aeronautics and Astronautics, Nanjing, 210016, China

2 Department of Mechanical Engineering, Faculty of Engineering and the Environment, University of Southampton, Highfield, Southampton, SO17 1BJ, UK

${ }^{3}$ School of Materials, The University of Manchester, Oxford Road, Manchester, M19 3PL, UK

*Corresponding author. Email: rjiang@ nuaa.enu.cn

\begin{abstract}
Pores and carbides inherited from SX superalloy manufacturing processes usually act as stress concentrators and are preferential sites for fatigue crack initiation. In this study, pore \& carbide size, morphology and distribution in a SX superalloy MD2 has been evaluated by X-ray CT. Strain accumulation and fatigue cracking behaviour in MD2, particularly around the pores and carbides, has been investigated by ex-situ SEM-DIC at room temperature along with image-based modelling of the observed MD2 defect populations obtained through X-ray CT imaging. The deformation structures have also been examined by electron channelling contrast imaging under controlled diffraction conditions. The results indicate that the pores \& carbides with complicated three-dimensional features are the dominant fatigue crack initiation sites. Deformation is concentrated within intense slip bands and an enhanced strain accumulation around pores is captured by SEM-DIC. Dislocation motion is mainly confined to the $\gamma$ matrix channels with some dislocation shear cutting of $\gamma^{\prime}$ precipitates also observed ahead of the crack tip. As the crack propagates, strain band density and dislocation density at the crack tip increases correspondingly. Image-based modelling using the observed defect populations in MD2 (micro)structure can effectively predict the stress concentrations and the resultant hot spot for subsequent fatigue crack initiation, which is consistent with the experimental observations.
\end{abstract}

Keywords: Ni-based single crystal superalloy; pores \& carbides; strain localisation; fatigue crack initiation; digital image correlation

\title{
1. Introduction
}


Ni-based single crystal (SX) superalloys are widely used in advanced turbine engines due to their excellent high temperature strength and exceptional resistance to fatigue, creep, oxidation and corrosion damage [1-3]. These SX superalloys are manufactured by directional solidification techniques followed by subsequent solid solution and precipitation hardening heat treatments to optimise the high temperature strength and the creep resistance. Due to the complicated alloy composition and usage of heavy elements such as W, Mo and Ta, the material inevitably contains defects such as shrinkage pores inherited from the solidification process $[1,4-6]$. Also, due to the addition of carbon to improve the castability, carbides are common features, located at the interdendritic regions [7-9]. These shrinkage pores and carbides are usually associated with fatigue crack initiation under service conditions and can influence fatigue crack propagation depending on the size of the pores and carbides, applied strain amplitude, test temperature and environment [4, 10-20]. This usually lowers the fatigue life of SX superalloys and introduces large fatigue life variability $[4,5,12,14,15,17,21]$. Generally speaking, in the high cycle fatigue test regime, crack initiation is quite sensitive to the existence of the pores and carbides and their size, shape and distribution $[16,18]$; in the high cycle fatigue test regime, cracks generally initiate from (internal) pores at relatively low strain amplitudes $[13,20]$, whereas cracks initiate from near surface pores, carbides and slip bands at relatively high strain amplitudes $[4,19,20]$.

It is widely accepted that the effect of pores and carbides on fatigue crack initiation is closely related to their size, shape and location/distribution, with the size of pores and carbides generally thought as the most critical parameter for crack initiation in casting alloys such as Al alloys and Ni-based SX Superalloys [4-6, 15, 16, 21-24]. Above a critical size, pores and carbides may play a decisive role in crack initiation by generating a localised stress concentration [5, 6, 23-25]. Studies have also shown the location to be important where pores and carbides located at, or close to, the surface are more detrimental to crack initiation than internal pores and carbides [22, 25, 26]. It is also believed that the shape of pores and carbides also influences the crack initiation process as the local radius is related to the degree of stress concentration $[6,25,26]$. However, many studies have been limited to traditional two-dimensional (2D) metallographic approaches that may introduce some bias in characterising the pore and carbide size and shape, as these do not consider the threedimensional (3D) nature of these features [27]. In particular, the complex 3D shape of carbides and porosities, and their distributions and concentrations in the bulk may also make an important contribution to fatigue crack initiation. 
Whilst it is clear that pores and carbides play a significant role in fatigue crack initiation, the mechanisms involved have not been fully captured experimentally. Currently, limited studies have been carried out to assess the full-field strain distribution around such pores and carbides to provide deeper insight into the crack initiation mechanisms. Recently, high resolution electron backscatter diffraction (HR EBSD) has been applied to study the residual elastic strains and geometrically necessary dislocation (GND) distribution around carbides and non-metallic inclusions in Ni-based SX superalloys and have shown enhanced localised strain and denser GND distribution around these defects [28-30]. Additionally, the full-field in-plane strain measurement technique of digital image correlation (DIC) has also been used to investigate strain localisation in polycrystalline Ni-based superalloys at the grain level with sub-micron resolution by using scanning electron microscopy (SEM) as the image acquisition system [31-34]. This recent development of HR EBSD and SEM-DIC provides a feasible methodology to map the localised strain distribution around the pores and carbides, thus enabling a more detailed understanding of the fatigue crack initiation mechanisms from these defects which are inherent to the manufacturing route.

To appreciate how fatigue cracks initiate in a Ni-based SX superalloy (i.e. MD2 alloy), this study uses ex-situ SEM-DIC and X-ray computed tomography (CT) imaging methods to provide a deeper understanding of the role of pores and carbides in strain localisation and fatigue crack initiation by linking the $3 \mathrm{D}$ microstructural features to the full field strain distribution. In this study, $\mathrm{CT}$ is used to quantify the porosity and carbide size and distribution within the SX superalloy MD2 and to qualitatively assess the 3D crack propagation. The strain accumulation and evolution in the SX superalloy MD2 under cyclic loading has been measured by SEM-DIC using secondary $\gamma^{\prime}$ as a natural speckle pattern. Special focus has been given to the strain accumulation around pores and carbides as these areas are preferential crack initiation sites. The interaction between cracks and pores has been assessed by X-ray CT image-based modelling to evaluate the stress concentrations generated around the pores and to predict likely sites for crack initiation. The deformation structures around the pores and carbides associated with crack initiation and at the crack tip have been examined to investigate the micro-mechanisms of crack initiation and propagation.

\section{Material and experimental procedures}

\subsection{Material and microstructural characterisation}

The SX superalloy MD2 used in this study was provided by GE Power. The composition (in wt.\%) of the MD2 alloy was $8.08 \mathrm{Cr}, 5.09 \mathrm{Co}, 5.05 \mathrm{Al}, 1.31 \mathrm{Ti}, 7.97 \mathrm{~W}, 2.04 \mathrm{Mo}, 6.0 \mathrm{Ta}$, 
$0.12 \mathrm{Hf}, 0.1 \mathrm{Si}, 0.0229 \mathrm{C}, 0.0066 \mathrm{~B},<0.05 \mathrm{Re},<0.01 \mathrm{Ru}, \mathrm{Ni}$ bal. The MD2 alloy was provided in the form of cylindrical rods with longitudinal orientation of $<001>$ after solution and precipitation hardening heat treatment in vacuum. Specimens were extracted from the MD2 cylindrical rods and prepared in a cube-cube orientation with the tensile axis aligned with the <001> crystallographic direction. Two coupon systems were prepared in this study, consisting of a dog-bone and plain bend bar specimen. The dog-bone specimens (Fig. 1(a) were used to evaluate strain localisation under cyclic loading using the SEM-DIC and the narrow $0.65 \times 0.65 \mathrm{~mm}$ cross-section was necessary to facilitate sufficient $\mathrm{X}$-ray transmission in the CT scans. The plain bend bar specimens (Fig. 1(d)) were used to further evaluate the deformation structures around the crack initiation sites and at the crack tips using electron channelling contrast imaging (ECCI) under controlled diffraction conditions.

(a)
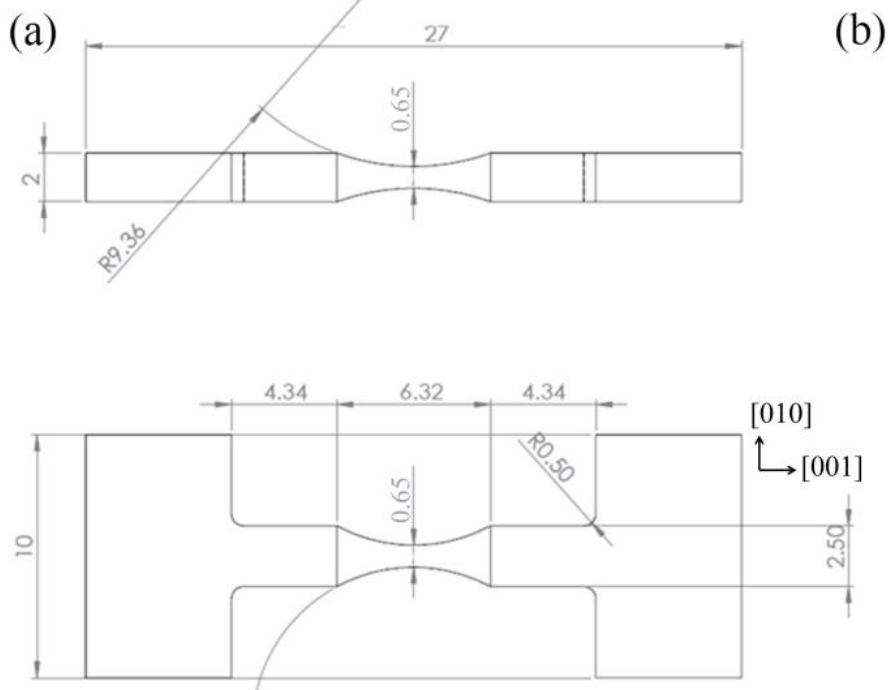

R6.65

(c)

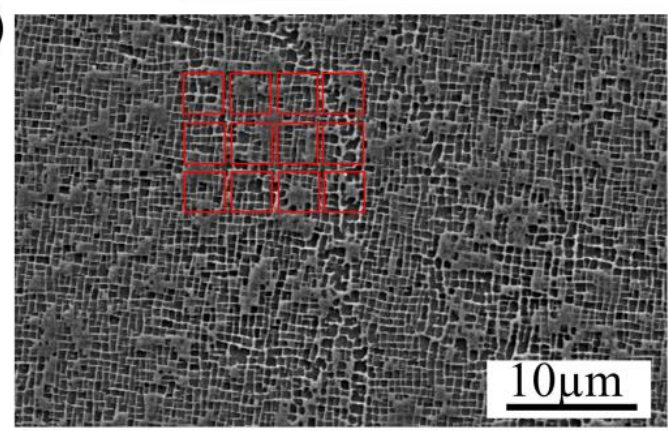

(b)

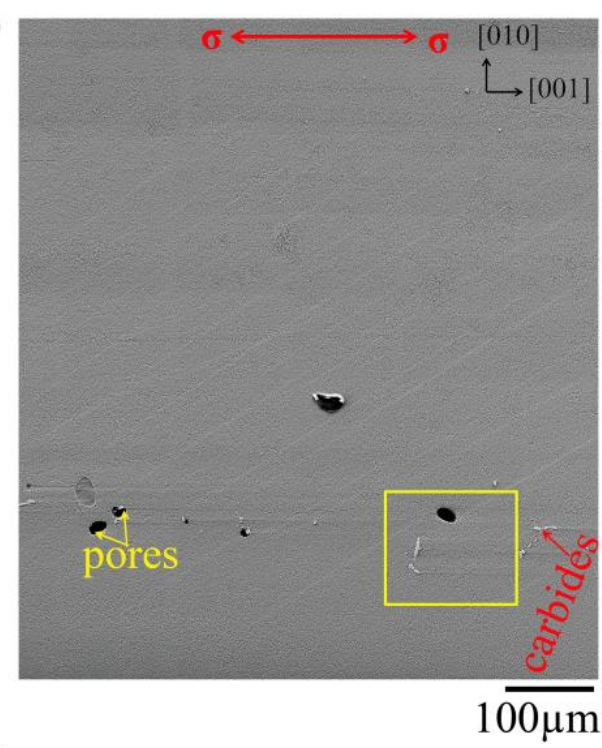

(d)

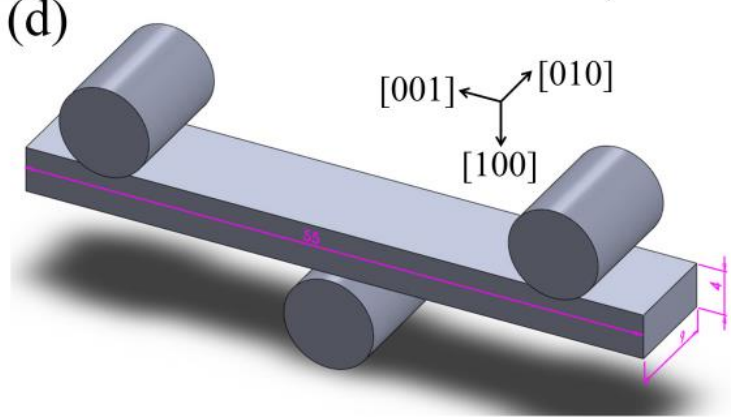

Fig. 1 Dimensions of (a) dog-bone specimen (in $\mathrm{mm}$ ); (b) gauge section in the dog-bone specimen after etching for SEM-DIC study of strain localisation; (c) Secondary $\gamma^{\prime}$ serving as speckle pattern for DIC analysis in the MD2 alloy. Subset windows (33 pixels $\times 33$ pixels) are indicated by the red squares. And (d) schematic diagram of three-point bending test. 
The MD2 alloy was etched by a reagent $\left(15 \mathrm{~g} \mathrm{CuSO}_{4}+50 \mathrm{ml} \mathrm{H}_{2} \mathrm{O}+3.5 \mathrm{ml} \mathrm{H}_{2} \mathrm{SO}_{4}+50 \mathrm{ml}\right.$ $\mathrm{HCl})$ for about 10 seconds after being ground and polished to reveal dendrite microstructures and carbides, and was electro-etched in a solution of $10 \%$ orthophosphoric acid in $\mathrm{H}_{2} \mathrm{O}$ at a voltage of $2 \mathrm{~V}$ for 25 seconds to reveal $\gamma^{\prime}$. The microstructures of the MD2 alloy were observed using an Olympus BH2 optical microscope (OM) and a JEOL JSM 6500F field emission gun (FEG) SEM. Two X-ray CT facilities were used to study the void and carbide distribution within the MD2 dog-bone specimens. These consisted of: synchrotron radiation computed tomography (SRCT) undertaken at the SPring-8 facility in Japan, and a laboratorybased XRadia Versa CT scanner within the $\mu$-VIS Centre at the University of Southampton. SRCT was used to understand both the pore and carbide geometry and distribution within the MD2 alloy within four dog-bone specimens to provide a statistically significant indication of the obtained pore and carbide distribution. Versa CT scanning was used to assess the short crack formation processes on the same SEM-DIC specimens to maximise observations across both techniques. The parameters for the CT scans are listed in Table 1. Porosity and carbide data were extracted from the CT volume using the ISO 50\% global threshold method [35]. To quantify porosity and carbide information, segmented data was processed using the ImageJ plugin BoneJ [36]. This enabled the pore and carbide volume size, sphericity and distribution to be quantified.

Table 1 Parameters for the CT scans conducted on SPring-8 Synchrotron CT and XRadia Versa CT

\begin{tabular}{|l|l|l|}
\hline Parameter & SPring-8 Synchrotron CT & XRadia Versa CT \\
\hline Energy & $53 \mathrm{kV}$ & 160 peak $\mathrm{kV}, 10 \mathrm{~W}$ \\
\hline Voxel resolution & $0.5 \mu \mathrm{m}$ & $0.79 \mu \mathrm{m}$ \\
\hline Scan time & 1.2 hours & $\sim 15$ hours \\
\hline Field of view & $\sim 1.0 \times 1.0 \times 1.0 \mathrm{~mm}^{3}$ & $\sim 0.8 \times 0.8 \times 0.8 \mathrm{~mm}^{3}$ \\
\hline Number of projections & $1800\left(180^{\circ}\right.$ rotation $)$ & $1501\left(360^{\circ}\right.$ rotation $)$ \\
\hline Exposure time & $2 \mathrm{~s}$ & $30 \mathrm{~s}$ \\
\hline Detector binning & $\times 1$ & $\times 2$ \\
\hline
\end{tabular}

\subsection{Fatigue tests}

Tension-tension fatigue tests were conducted on the dog-bone specimens on an Instron Electro-plus testing machine at room temperature with a $20 \mathrm{~Hz}$ sine waveform and a load ratio of 0.1 . A maximum nominal stress of $\sim 85 \%$ yield was applied and calculated based on the measured cross-section determined from optical measurements at the narrowest region in the gauge section. The gauge section in the dog-bone specimens was ground with 400,800 and 1200 grit $\mathrm{SiC}$ abrasive papers, then polished with $1 \mu \mathrm{m}$ diamond polishing paste. A JEOL 
FEG SEM JSM6500F was employed to examine the fracture surface to identify the crack initiation sites.

One dog-bone specimen was etched in the chemical solution of $15 \mathrm{~g} \mathrm{CuSO}_{4}+50 \mathrm{ml} \mathrm{H}_{2} \mathrm{O}+$ $3.5 \mathrm{ml} \mathrm{H}_{2} \mathrm{SO}_{4}+50 \mathrm{ml} \mathrm{HCl}$ for 30 seconds to reveal the $\gamma^{\prime}$ which provided the speckle pattern for ex-situ SEM-DIC investigation of strain localisation under cyclic loading. The final crosssection of the gauge section was approximately $0.65 \mathrm{~mm} \times 0.65 \mathrm{~mm}$. Reference images were taken at the gauge section using a JEOL FEG SEM JSM6500 machine under the secondary electron imaging (SEI) mode before the fatigue tests. The SEM imaging parameters used are shown in Table 2 following guidelines proposed by the literature [34, 37-39]. The SEM images taken from the gauge section were stitched together using Fiji software [40]. The stitched image is shown in Fig. 1 (b). The morphology of $\gamma^{\prime}$ (i.e. speckles for DIC analysis) along with the used subset is shown in Fig. 1 (c). Once the reference images were taken, fatigue tests were conducted and interrupted after certain loading cycles to capture the SEM images in the ex-situ (unloaded) deformed gauge section. The observation history of this SEM-DIC specimen is taken sequentially at 10000 cycles $\rightarrow 20000$ cycles $\rightarrow 30000$ cycles $\rightarrow 40000$ cycles $\rightarrow 50000$ cycles $\rightarrow 55000$ cycles. The fatigue tests were stopped before fracture for X-ray CT examination of 3D crack morphology and the interaction between cracks and pores/carbides using the XRadia Versa CT scanner. The parameters used for this scanning are listed in Table 1 . Cracks were segmented semi-automatically using the seeded region growing tool in VG-studio Max.

Table 2 Imaging parameters in JEOL FEG SEM JSM6500F

\begin{tabular}{|c|c|c|c|c|c|c|}
\hline $\begin{array}{l}\text { Imaging } \\
\text { mode }\end{array}$ & $\begin{array}{l}\text { Acceleration } \\
\text { voltage }\end{array}$ & $\begin{array}{l}\text { Probe current } \\
\text { spot size }\end{array}$ & $\begin{array}{l}\text { Imaging } \\
\text { time }\end{array}$ & $\begin{array}{l}\text { Working } \\
\text { distance }\end{array}$ & Image size & $\begin{array}{l}\text { Pixel } \\
\text { size }\end{array}$ \\
\hline SEI & $15 \mathrm{kV}$ & 13 & $80 \mathrm{~s}$ & $9.9 \mathrm{~mm}$ & $1280 \times 1024$ & $93.5 \mathrm{~nm}$ \\
\hline
\end{tabular}

\subsection{Image-based modelling approach}

To understand better the nature of the stress concentration around the pores, image-based modelling was conducted. This approach models the exact 3D geometry of the test specimen features obtained from the CT data. Simpleware ScanIP software was used to generate a 3D mesh of the component geometry taken from a CT scan of the dog-bone specimen. This resulted in a mesh of approximately one million tetrahedral elements consisting of a global mesh size of $0.1-0.3 \mathrm{~mm}$ and local mesh refinement around the porosities of $0.8 \mu \mathrm{m}$. Finite 
element modelling software ABAQUS was used to apply a static tensile load equivalent to $85 \%$ of the yield stress of MD2 alloy to the generated mesh to simulate the peak stress of a tensiletensile cyclic load. A linear elastic model was used, and the employed elastic constants C11, C12 and C44 are 171 GPa, 104.4 GPa and 103.5 GPa respectively [41].

\subsection{Ex-situ SEM-DIC characterisation of strain accumulation}

DIC analysis was carried out using MatchID commercial software. Due to the ex-situ nature of the SEM-DIC used in this study, a noise sensitivity study was performed. Details of the noise assessment of ex-situ SEM-DIC can be found in a previous publication [33]. Based on the noise sensitive study, a subset of $33 \times 33$ pixels (i.e. $3.084 \mu \mathrm{m} \times 3.084 \mu \mathrm{m}$ at 1000 magnification) and a step size of 7 pixels were chosen for the DIC analysis. The subset size gave a good compromise between noise and spatial resolution. The step size gave a good balance between computational efficiency and accuracy to capture local peaks in strains. Other DIC parameters are the same as those used in our previous study [33]. To simplify the comparisons between different shear band orientations, the maximum shear strain has been calculated. This is the radius of Mohr's circle and is independent of the coordinate system. The maximum shear strain is given by the following equation:

$$
\varepsilon_{x y}^{\max }=\sqrt{\left(\frac{\varepsilon_{x x}-\varepsilon_{y y}}{2}\right)^{2}+\varepsilon_{x y}^{2}}
$$

\subsection{Deformation structure characterisation}

Deformation structures around the crack initiation sites and at the crack tip were examined by ECCI under controlled diffraction conditions in a Zeiss Sigma FEG-SEM operating at $20 \mathrm{keV}$ and a high probe current. This analysis was performed on the plain bend bar specimens shown in Fig. 1 (d). To prepare the surface, plain bend bar specimens were ground with 180, 800, 1200 and 4000 grit $\mathrm{SiC}$ abrasive papers, and polished with $0.05 \mu \mathrm{m}$ colloidal silica before the fatigue test. Interrupted three point bending fatigue tests were conducted on the plain bend bar specimens on an Instron 8501 hydraulic testing machine at room temperature with a $20 \mathrm{~Hz}$ sine waveform and a load ratio of 0.1 . The distance between the top two rollers was $40 \mathrm{~mm}$ with a roller located at the bottom at the mid-point. The applied load was chosen to produce a maximum stress of $90 \%$ yield stress on the top central surface based on simple beam theory calculation. After the fatigue test, the specimens were re-polished with $0.05 \mu \mathrm{m}$ colloidal silica for 20 minutes prior to ECCI examination of dislocations at the crack initiation sites and at the crack tips. In comparison to transmission electron microscopy (TEM) for the characterisation of deformation structures (i.e. dislocations), the advantages of 
ECCI are that we are able to observe a much larger area than a TEM foil and that the technique only requires a well-polished specimen surface. Furthermore, the site-specific observation of the deformation structures in the crack tip process zone is a major advantage, as this avoids any constraint relief artefacts that may result from TEM foil extraction at the crack tip.

Accurate sample orientation information was obtained by EBSD at $70^{\circ}$ to the sample surface normal and subsequent simulation of the electron channelling pattern (ECP) at $0^{\circ}$ with software TOCA (Tools for Orientation Determination and Crystallographic Analysis) $[42,43]$. Any uncertainty in the orientation through misalignment of the EBSD system was corrected by a calibration of the ECP and EBSD patterns with single crystal Si. The ECP can be directly observed in back-scattered electron (BSE) mode on single crystals at $0^{\circ}$ and at low magnification. With careful system alignment, it is possible to observe single dislocations when the sample is rotated and tilted into a two-beam condition in BSE mode. These principles of ECCI for dislocation observation can be found in a recent review by Zaefferer [44]. In the present work, the condition $\mathrm{g}=020$ was used exclusively.

\section{Results}

\subsection{Microstructures of MD2 alloy}

Fig. 2 shows representative elements of the microstructure of MD2 alloy. One relevant feature as shown in Fig. 2 (a) is the presence of interdendritic carbides and pores, which can be seen more clearly in Figs. 2 (b) and (c). The carbides located in the interdendritic region have a "blocky" or "script" morphology and are enriched in Ta and Hf as indicated by the EDX analysis shown in Fig. 2 (d), whereas the small and relatively circular carbides located in the pore are mainly Mo/W-rich carbides as indicated by the EDX analysis shown in Fig. 2 (e). Two distinct pore types can be seen in Fig. 2 (c). The elongated, irregular shaped pores, are known as shrinkage porosities which form during the final stages of the solidification process [45]. The more spherical, smaller pores are known as gas pores [46]. Figs. 2 (f) and (g) show the morphology and distribution of secondary and tertiary $\gamma^{\prime}$ in the MD2 alloy, from which we can see that the secondary $\gamma^{\prime}$ has a cubic morphology and tertiary $\gamma^{\prime}$ has a circular morphology. 

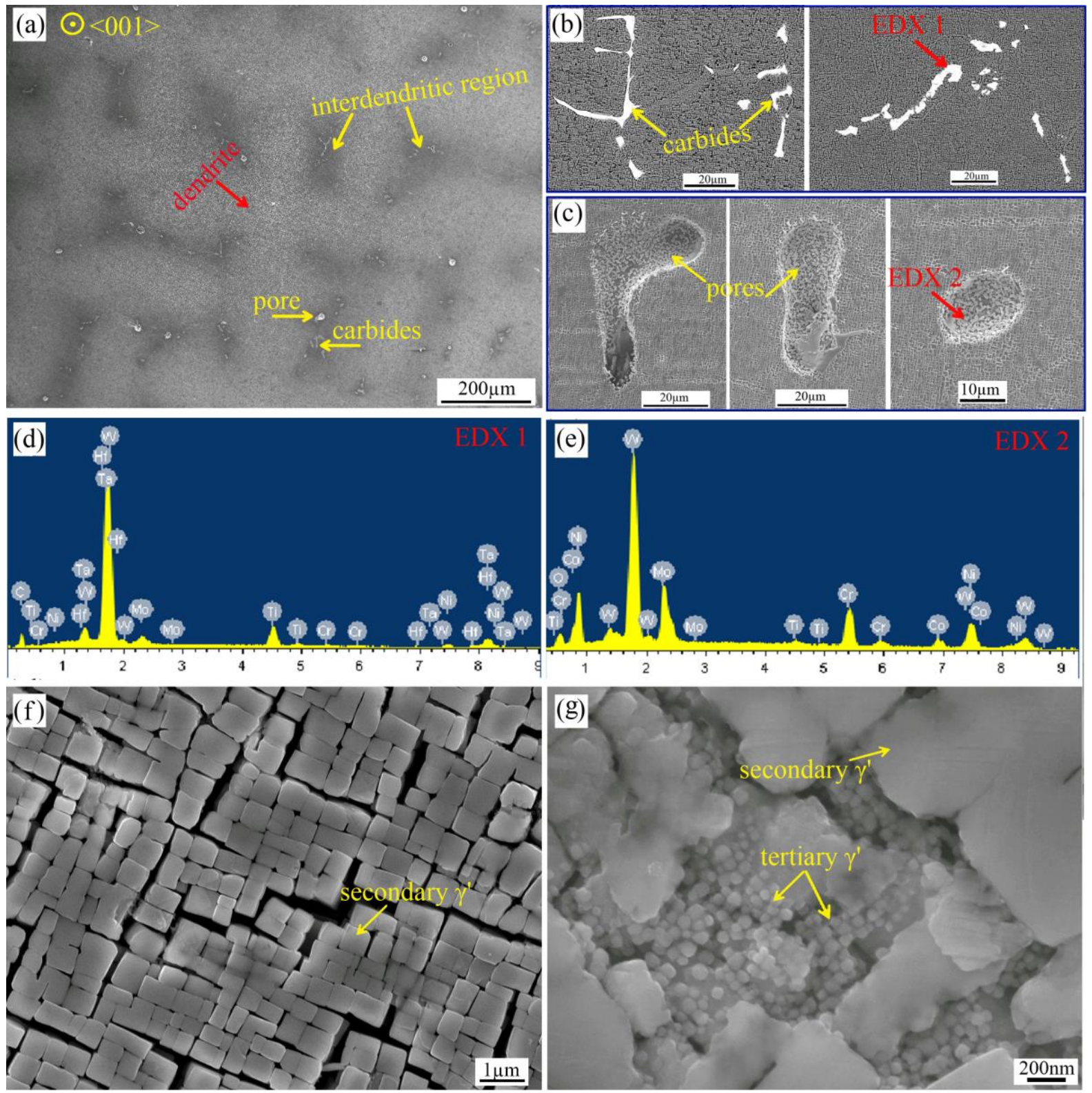

Fig. 2 Microstructures of MD2 alloy: (a) dendrite structures; (b) carbides and (c) pores at the interdendritic region; (d) EDX analysis of the script carbides; (e) EDX analysis of the carbides locating within the pore; (f) secondary $\gamma^{\prime}$ and (g) tertiary $\gamma^{\prime}$.

The 3D renderings obtained from SRCT are presented in Figs. 3 (a) and (b) and show the porosity and carbide distribution within the MD2 alloy respectively. The distribution of pores and carbides are both shown to congregate within the interdendritic regions. This can be further confirmed by the distribution plot in Fig. 3 (c) which shows carbide and pore distribution when projected to a plane that is normal to the solidification direction (i.e. $<001>$ ) of the MD2 alloy. In essence, the occurrence of a pore is likely to be in close proximity to carbides, with locally dense and sparse distributions of these constituents. This is consistent with the $2 \mathrm{D}$ observations in $\mathrm{OM}$ and SEM and indicates that X-ray CT provides adequate 
resolution to capture the pores and carbides in this directionally solidified single crystal Nibased superalloy. The size distribution of pores and carbides can be seen in Figs. 3 (d) and (f). Porosity and carbides come in a range of different shapes and sizes. These can be simplified in statistical approaches to understand the distribution of pore size (Fig. 3 (d)) and poresphericity (Fig. 3 (e)), an indication as to the elongation of the pore. Regarding pore and carbide size, the majority of pores and carbides are smaller than $2000 \mu \mathrm{m}^{3}$ and $4000 \mu \mathrm{m}^{3}$ respectively. Above this level, there are only a handful of very large pores (four in total) 4000-23000 $\mu^{3}$. Whilst pore size and elongated shape (sphericity) can be quantified simplistically, it should be highlighted that real pores can be more complex in geometry and therefore are difficult to describe with these simple quantification parameters. Fig. 3 (e) shows a representation of spherical and elongated pores through to more complex pores.

\subsection{Strain localisation and crack initiation}

For the fatigue tests conducted on the dog-bone specimens, the fatigue life ranges from $31 \mathrm{k}$ to $170 \mathrm{k}$ cycles. The scatter of the fatigue life is attributed to the variation in size, shape and location of the defects (such as pores and carbides) associated with crack initiation. In addition, it is possible that when determining the nominal maximum applied stress $(85 \%$ yield), measurement error of the dog-bone cross-section may also contribute to scatter in fatigue life. Whilst this paper has shown significant scatter in fatigue life, the aim of the current study is not to directly assess the scatter but to focus on the microstructural features that are closely related to the crack initiation process. As shown in Fig. 4, cracks generally initiate from inclusions (Fig. 4(a)), large surface carbide clusters (Fig. 4(b)) and pores (Figs. 4(c) and (d)), based on the observation of the fracture surfaces in SEM under the BSE mode. In general, it seems that reduced fatigue lives are associated with large near surface defects. In addition, as indicated by the carbide morphology on the fracture surface, it seems that carbide cleavage rather than decohesion at the carbide/matrix interface is responsible for crack initiation. Crystallographic facets can be discerned around pores and carbides, indicating that stage I crack propagation sets in after crack initiation. 


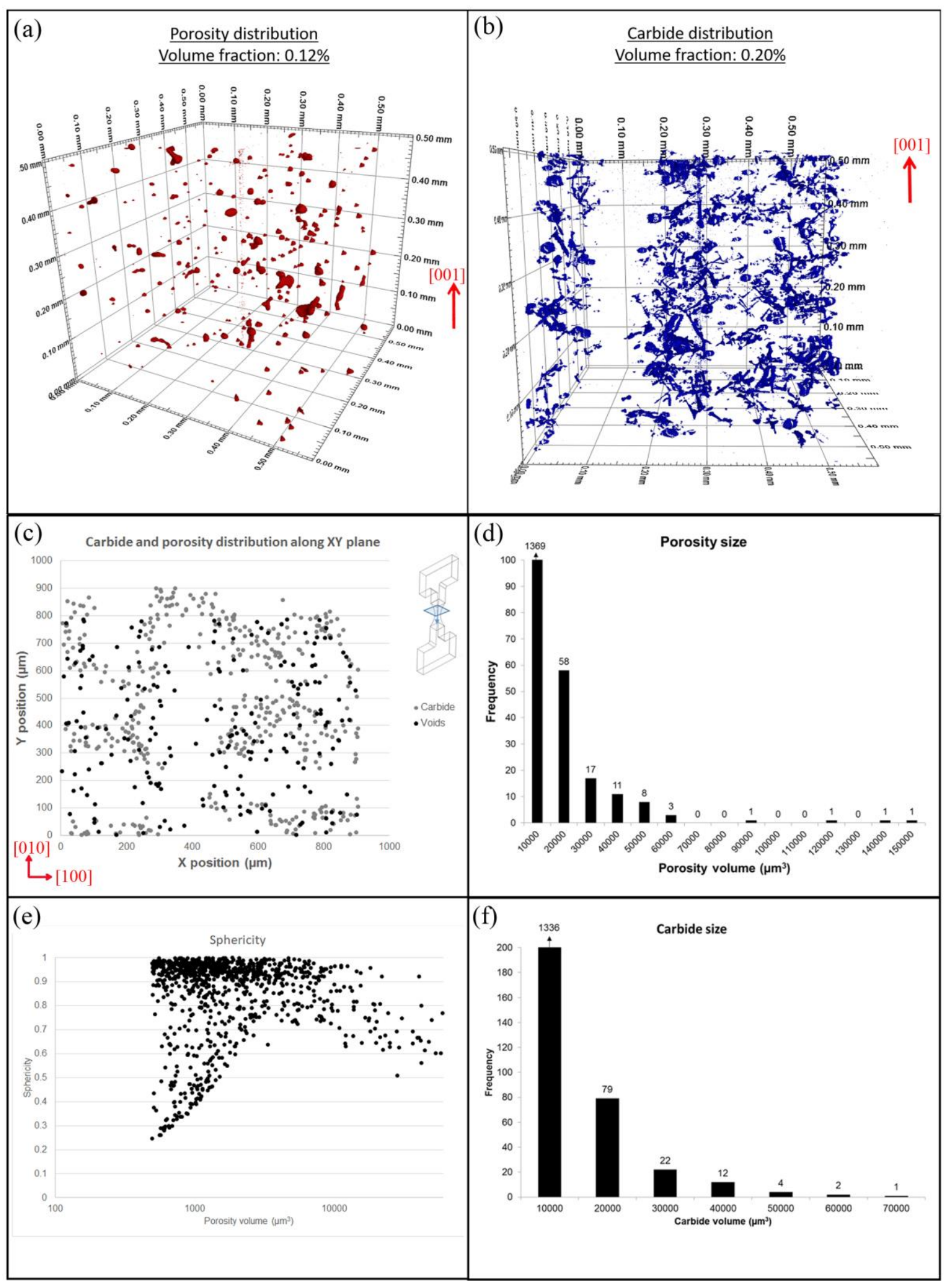

Fig. 3 SRCT characterisation of pores and carbides in MD2 alloy: (a) pore distribution in 3D; (b) carbide distribution in $3 \mathrm{D}$; (c) projection of the pores and carbides to a plane normal to 
the solidification direction of MD2 alloy; (d) quantified statistical distribution of pore size; (e) pore sphericity; and (f) quantified statistical distribution of carbide size.

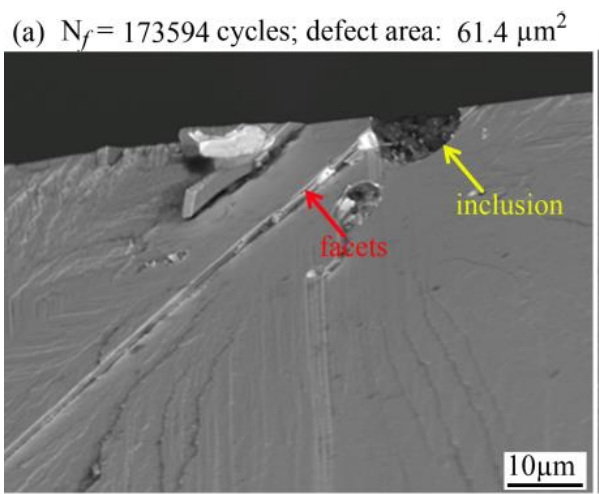

(b) $\mathrm{N}_{f}=48910$ cycles; defect area: $752.3 \mu \mathrm{m}^{2}$

(c) $\mathrm{N}_{f}=67859$ cycles; defect area: $551.1 \mu \mathrm{m}^{2}$
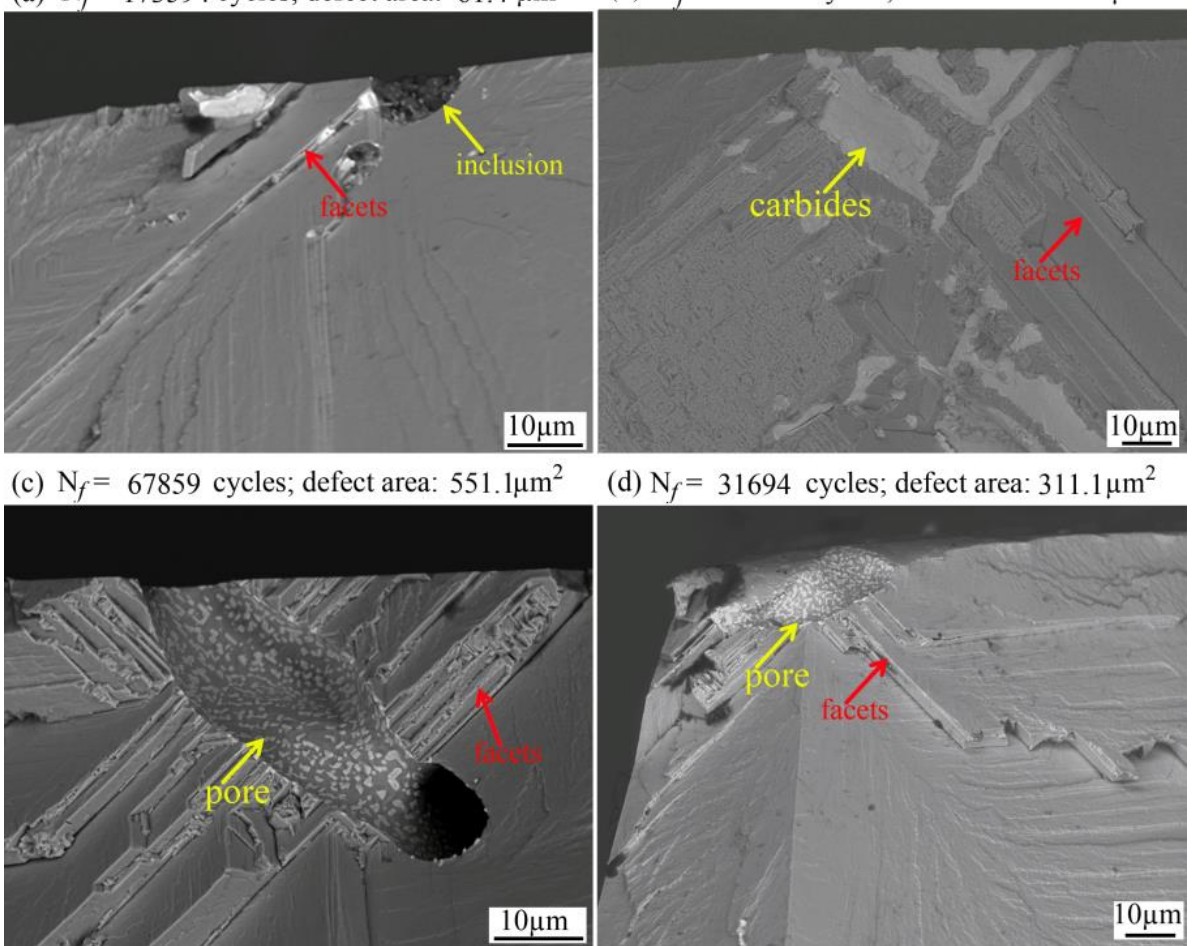

(d) $\mathrm{N}_{f}=31694$ cycles; defect area: $311.1 \mu \mathrm{m}^{2}$

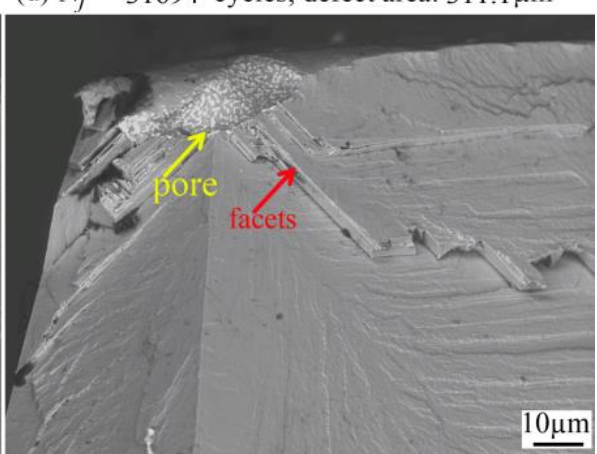

Fig. 4 Fatigue crack initiation sites in MD2 SX superalloy observed in SEM under the BSE mode: (a) crack initiation from inclusion; (b) crack initiation from carbides; (c) and (d) crack initiation from pores.

Strain accumulation under cyclic loading in the dog-bone specimens was investigated by ex-situ SEM-DIC with a focus around pores and carbides. Fig. 5 shows the maximum shear strain evolution in the whole gauge section in the dog-bone specimen, from which we can see the bands of concentrated strain. These bands of concentrated strain are believed to be associated with the formation of slip bands. Hereafter, these bands containing concentrated strains are designated as strain bands for ease of description. The strain bands are clearly visible in the maximum shear strain maps, and show an inclination angle of $\sim 45^{\circ}$ with respect to the loading direction. In the first two interruptions, there was no apparent increase in the magnitude of strain within the strain bands or in the strain band density (see Figs. 5 (a) and (b)). After 50000 cycles, more strain bands appeared, indicating that cyclic damage further developed. On further cyclic loading of the specimen by another 5000 cycles to 55000, we can see an evident strain increase and new strain bands can be observed. This strain increment can be seen more clearly in Fig. 5 (e), which uses the SEM images taken after 50000 cycles as the reference image, and correlates the images taken after 55000 cycles. This 
significant "apparent strain" increase is caused by crack initiation at 50000 cycles based on the interrupted observation in the SEM and then propagates in the following loading cycles. The morphology of the cracks and the deformed microstructures at the crack tip at the end of the interrupted test are shown in Figs. 5 (f) - (j). Figs. 5 (f) and (g) show the crack morphology, from which we can see the straight crack path segments. These straight crack path segments are aligned with the strain bands captured by SEM-DIC. Also, crack deflection can be seen at certain locations. Fig. 5 (h) shows that the crack interacts with the carbides during propagation, and intensive deformation around the carbides is discerned as indicated by the dense slip bands shown in Fig. 5 (i). It should be noted that this intensive deformation in terms of the slip bands is not clearly shown in the strain maps in Fig. 5 (d). This might be related to the size of the natural speckle pattern being too large to provide a high enough spatial resolution indicating some limitations of the technique. The microstructures at the crack tip are shown in Fig. 5 (j). It is found that intensive slip bands cut through the $\gamma^{\prime}$ and these slip bands show a feature of extrusion as indicated by the contrast difference in the secondary electron images. These slip bands appear to be consistent with the strain bands shown in Figs. 5 (d) and (e).

A close-up of the strain localisation around the pore associated with crack initiation is presented in Fig. 6 with modified scale to highlight the strain accumulation around the pores. Due to a lack of a natural speckle pattern within the pore, the latter was excluded from the DIC analysis to get more reliable strain distribution around it. As shown in Fig. 6 (a), a slight enhanced strain accumulation is discerned at the bottom right edge of the pore, which might be associated with the impingement of the slip band with the pore. In addition, the intersection of two slip bands also causes a higher localised strain. With the loading cycles increasing from 10000 cycles to 20000 cycles, an apparent strain accumulation appears at the lower edge of the pore, especially in the $\varepsilon_{y y}$ and $\varepsilon_{x y}$ strain component, even though there is no apparent increase in strain value in the strain bands in the matrix as shown in Figs. 5 (a) and (b). However, it is noted that we should be careful about the interpretation of the strain distribution around the edges of pores due to an incomplete speckle pattern within the subset caused by the subset crossing the boundary between the pore and speckled region. Moreover, it is noted that the surface regions with greater strain do not directly lead to crack initiation through the SEM observations during the interrupted test. In this particular case, the crack initiated within the pore (shown in Fig. 7) and is not captured by the in-plane surface 
measurement by SEM-DIC as shown in Figs. 5 and 6. Once initiated, the crack propagates along the two strain bands to the left of the pore.
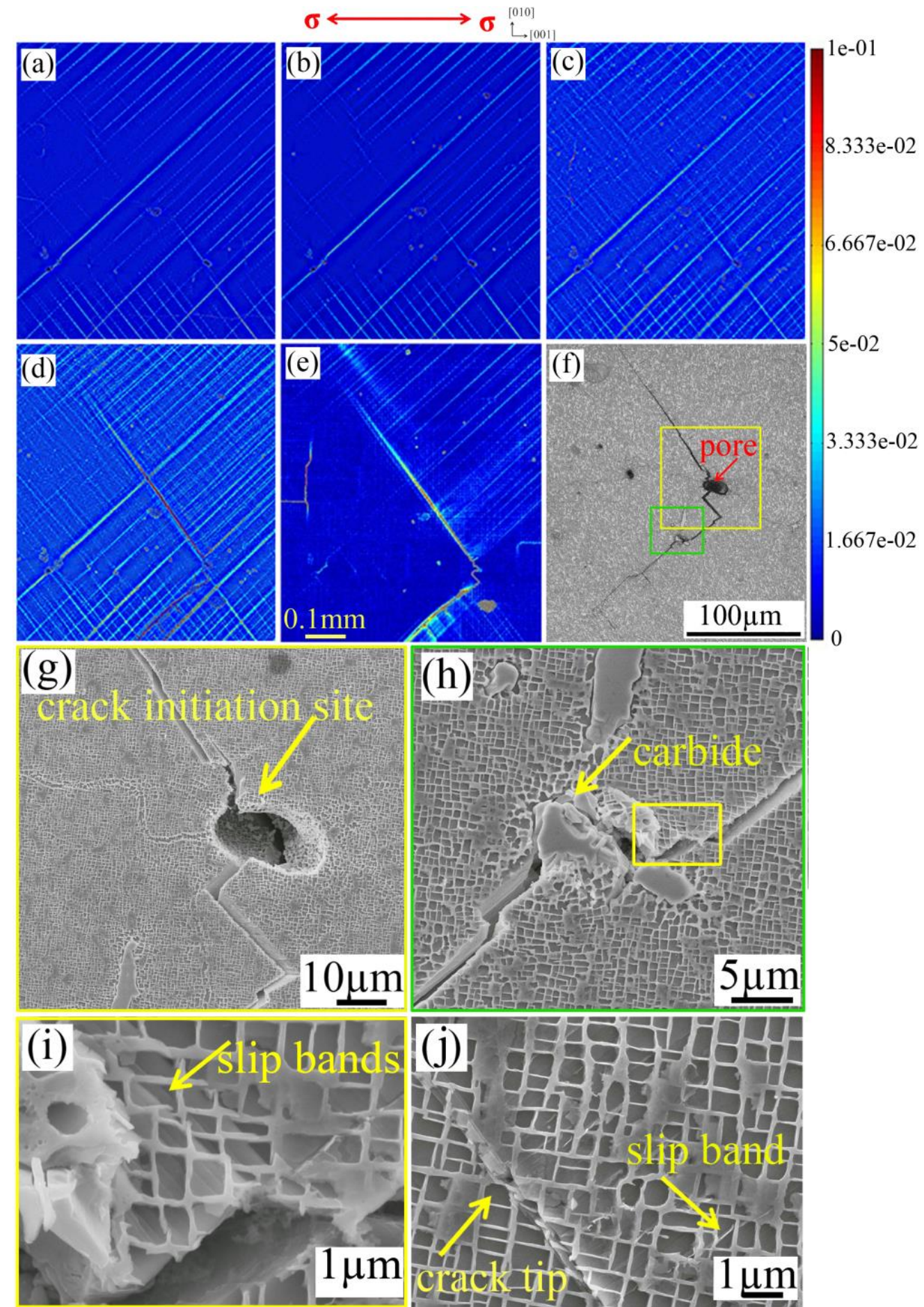

Fig. 5 Strain evolution under the cyclic loading in the gauge section: maximum shear strain map at the following number of cycles: (a) 10000; (b) 20000; (c) 50000; (d) 55000; and (e) increment from 50000 to 55000 cycles; secondary electron images of: (f) crack path; (g) pore associated with crack initiation; (h) carbides located on the crack path; (i) close-up of the 
region highlighted by rectangle in (h); and (j) morphology of the crack tip, slip band extrusion can be seen as indicated by the white lath in primary $\gamma^{\prime}$ indicated by the arrow. 
(a) 10000 cycles $\boldsymbol{\sigma}$
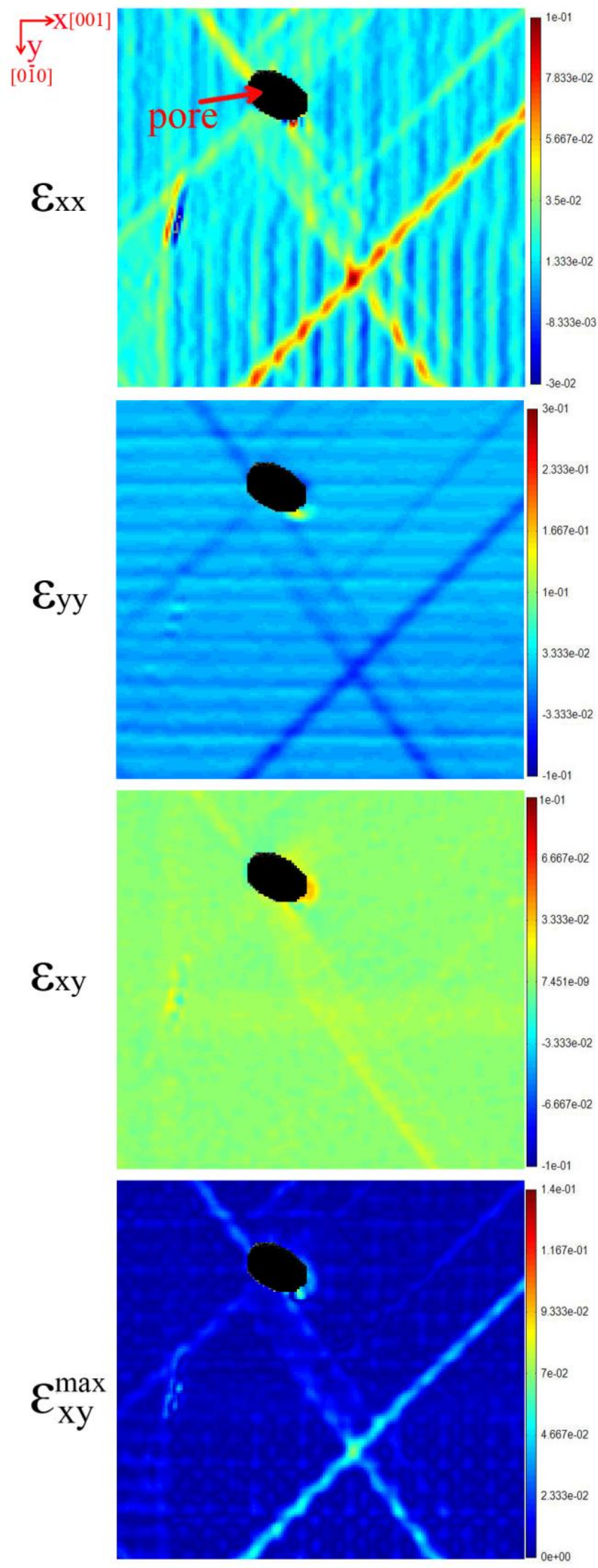

(b) 20000 cycles
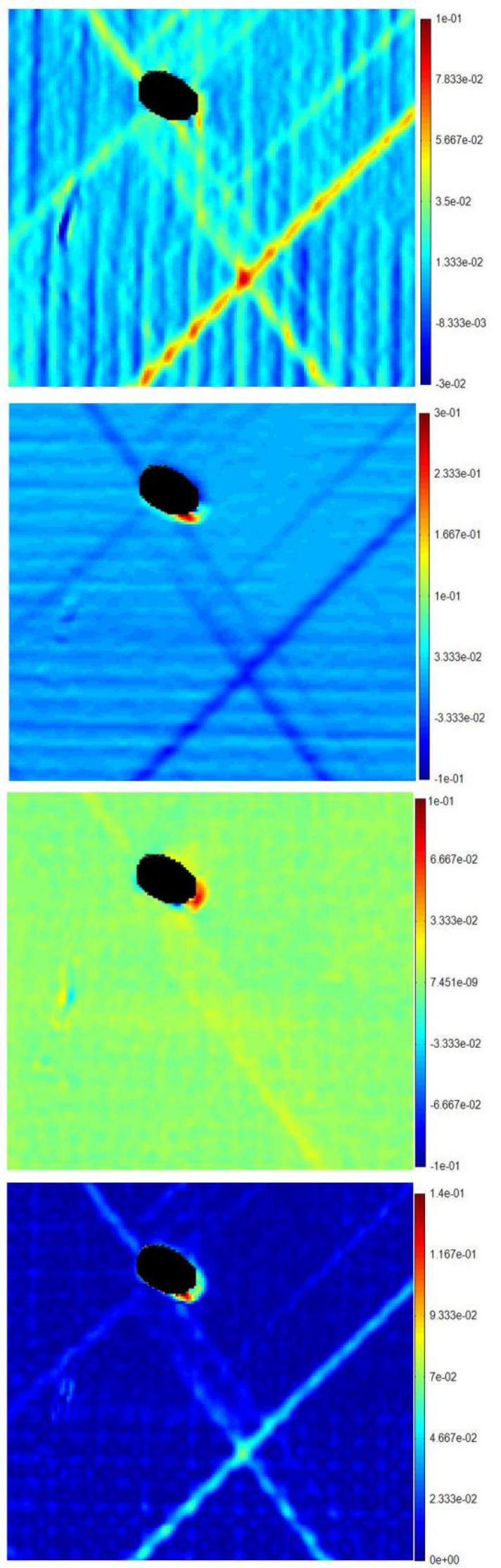

Fig. 6 Strain accumulation around the pore in AOI at (a) 10000 cycles and (b) 20000 cycles. 
To enable better understanding of the role of pores and carbides in fatigue crack initiation, the 3D morphology of the same crack shown in Fig. 5 (f) is presented in Fig. 7 (a), showing the interaction between the crack and nearby pores and carbides. As shown in Fig. 7 (a), the crack initiates at the pore. This is also verified by the SEM observation during the interruption of the test at 50k cycles as shown in Figs. 7 (b) and (c). Some carbides can be discerned around the pore and are present within $100 \mu \mathrm{m}$ from its surface. The crack shows a faceted "V" shape, and each flank has an inclination angle of $\sim 45^{\circ}$ with respect to the loading direction, which indicates the crack propagates along the slip plane/band. This is consistent with the early SEM observation during interruption shown in Fig. 7 (d). On the crack plane, we can see carbide clusters located at the crack path, resulting in a small deflection of the crack path. Additionally, the absence of cracking from the two large sub-surface pores nearby indicates the location of the pore is critical to crack initiation process.

(a)

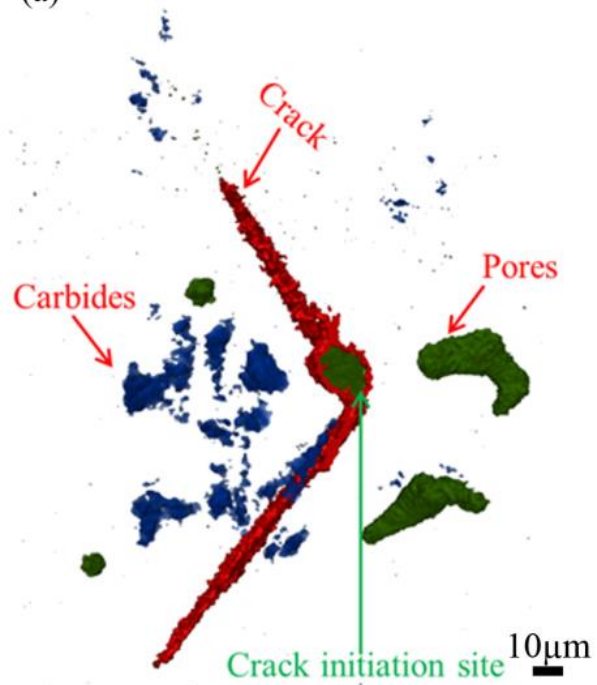

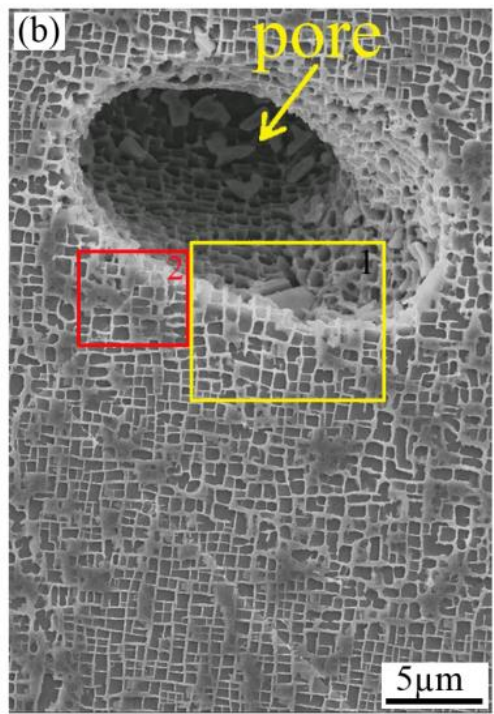

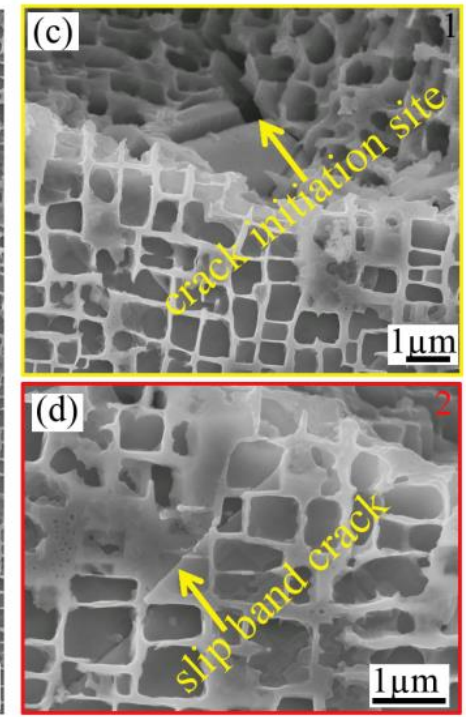

Fig. 7 (a) X-ray CT examination the 3D crack morphology at 55k cycles; (b) crack initiation at the bottom of the pore at 50k cycles; (c) and (d) close-up of crack initiation site and slip band crack in the regions highlighted in (b).

To complement the observations of cracks from CT data and strain accumulation work, image-based modelling was conducted to observe the stress concentrations surrounding the pores. Using the geometries of the specimen features obtained from CT, the porosity shapes can be modelled to predict the stress concentrations forming around these features. Fig. 8 shows the overview of the dog-bone specimen when $85 \%$ of yield stress load is applied. Four porosity regions were observed from the surface as shown. The stress concentration factors from the model are calculated as: 1.67, 2.66, 2.03 and 3.57 for porosity regions 1-4 respectively. The porosity shown in region 4 is of the same region of interest studied with ex- 
situ SEM-DIC. Here it is clear a ridge within the geometry of the pore has generated a significant localised stress concentration compared to the other pores in the model. This correlates with the crack initiation observed in the SEM, where the crack was observed to initiate within the depth of the pore (Fig. 7), and the X-ray CT showing the crack propagating into the bulk (Fig. 7).

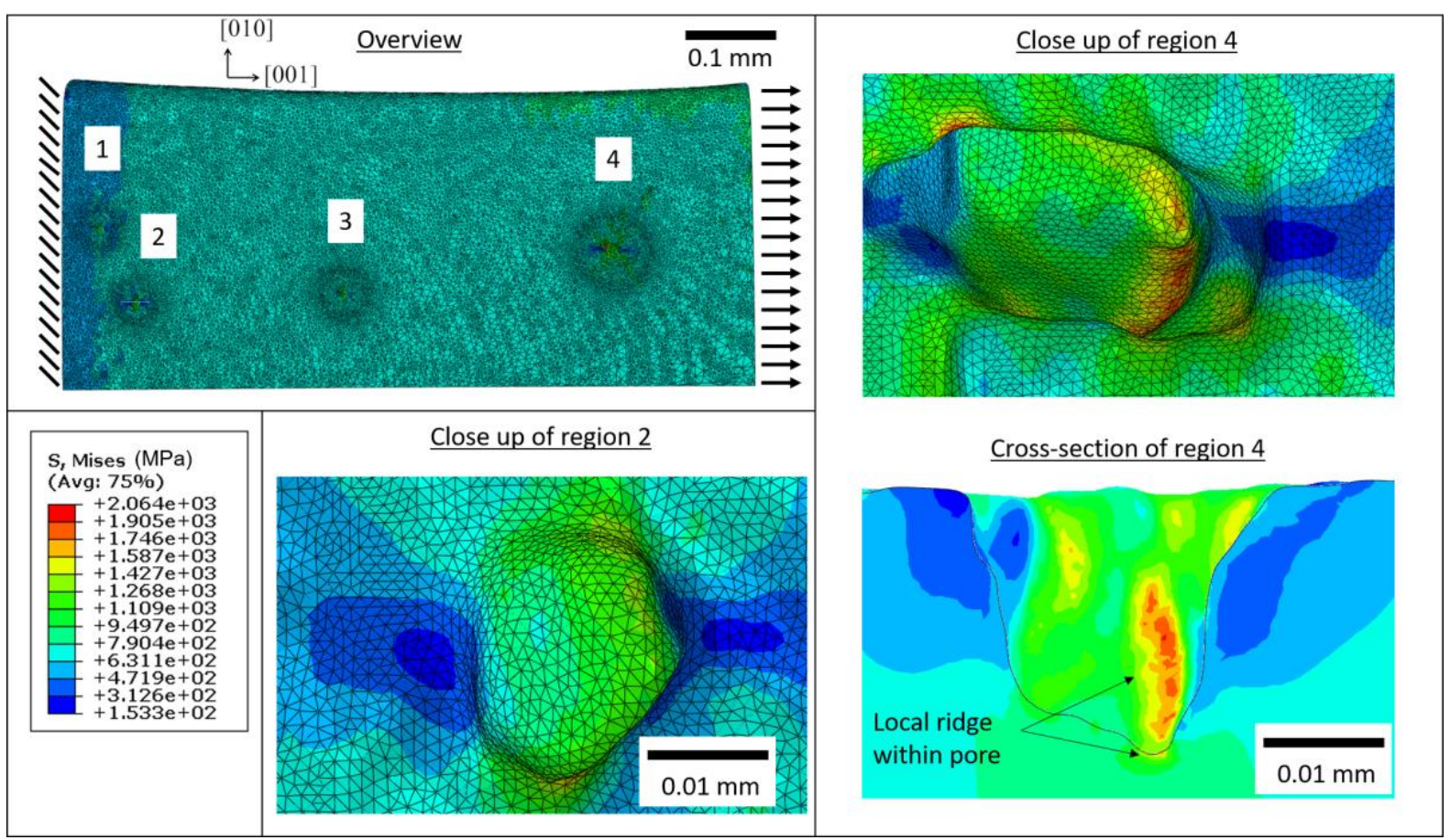

Fig. 8 Image-based modelling of the stress concentration around the surface pores. The pore associated with crack initiation (region 4) shows the most significant stress concentration.

\subsection{Deformation structures}

Fig. 9 shows the deformation structures in the plain bend bar specimen, characterised by ECCI under controlled diffraction conditions and imaging with the diffraction vector $\mathrm{g}=020$. Similarly to the dog-bone specimen, the crack preferentially initiates from pores as shown in Fig. 9 (a). It appears that dislocations are mainly distributed in the $\gamma$ channel. Due to the stress concentration effect around the pore and carbides, the lattice misorientation is high causing an over-exposed high contrast region immediately at the interface between the pore and the $\gamma /$ $\gamma^{\prime}$ matrix. In Figs. 9 (b) and (c) we demonstrate that the dislocation density is much higher immediately adjacent to these regions in comparison to further from the crack. At the crack tip (Fig. 9 (d)), intensive deformation along with local lattice misorientation can be discerned, and the dislocation density is even higher than that adjacent to the pore where the crack initiated. Whilst there is some dislocation shear-cutting of $\gamma^{\prime}$ in the deformation zone directly ahead of the crack tip (Fig. 9 (e)), this is not the case just adjacent to this region parallel to the 
crack path (Fig. 9 (f)). In Fig. 9 (f) we show that dislocations glide in the $\gamma$ channel; here, a layer of $\gamma$ matrix remains on the surface after polishing, which provides clear observation of the distribution of dislocations in the $\gamma$ matrix as shown in Fig. 9 (g).

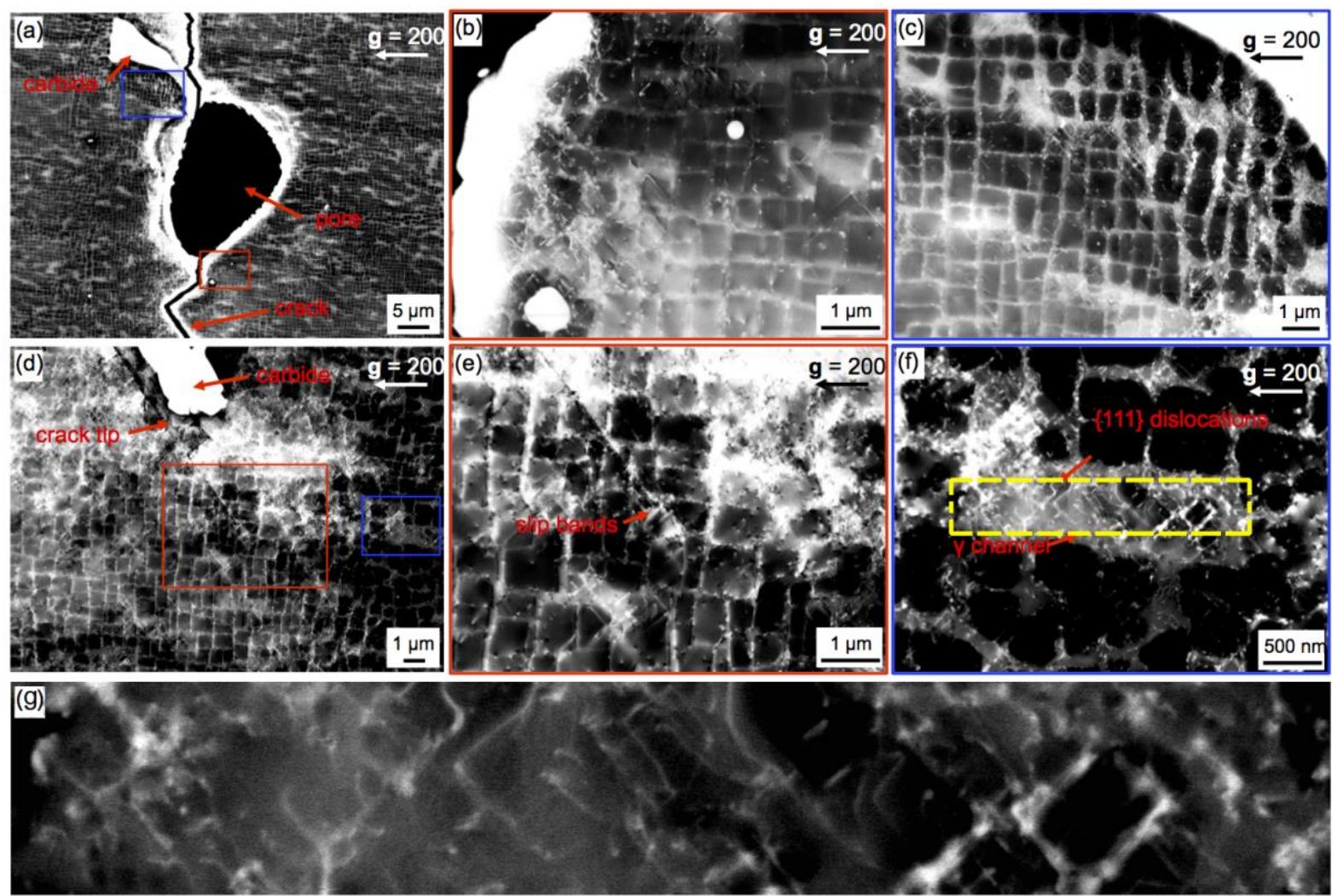

Fig. 9 Deformation structures observed at the crack initiation site and at the crack tip using ECCI under controlled diffraction conditions: (a) crack initiated from a pore in the plain bend bar specimen; (b) and (c) close-up of the regions highlighted by rectangles in (a); (d) crack tip morphology; (e) and (f) close-up of regions highlighted by rectangles in (d); (g) close-up of the dislocations in the $\gamma$ channel as indicated in (f) by the yellow rectangle.

\section{Discussion}

As shown in this study, fatigue cracks mainly initiate from carbides and pores in SX superalloy MD2 at room temperature. These crack initiation features are widely observed in casting and directionally solidified Ni-based superalloys [4, 5, 21]. Large fatigue life variability is observed depending on the size, morphology and distribution of carbides and pores (Fig. 4). Generally speaking, it is expected that large carbides and pores on the surface or close to the surface will dominate the crack initiation process. But it is noteworthy that the size of the feature responsible for fatigue crack initiation could not be directly related to the fatigue life as shown in Figs. 4 (c) and (d) and as also illustrated in the literature [21]. The 
variability of pore and carbide size, shape and distribution all contribute towards variability in the number of cycles to initiate a crack and the subsequent cycles to failure. This makes it difficult to predict the number of cycles before crack initiation and the location where the crack will initiate. Traditional 2D evaluation of the size, morphology and distribution of carbides and pores may bring about a bias which will hinder appropriate correlation between the true pore/carbide distribution and its link to fatigue life variability. 3D characterisation of carbides and pores thus provides a more accurate investigation of the role and effect of carbides and pores in fatigue crack initiation. Based on the 3D characterisation of carbides and pores, image-based FE modelling can be conducted to simulate the stress and strain response of the carbides/pores-containing specimens upon monotonic or cyclic loading, and to assist understanding and prediction of the failure processes related to the pores and carbides [23, 24, 47]. As shown in this study, by combining the experimental study with image-based modelling (Figs. 7 and 8), the observed initiation of the crack corresponded to the simulation results showing the pore with greatest stress concentration factor did act as the initiating feature. In addition to this observation, the image-based modelling work has revealed that the complex shape of the porosity needs to be considered. In this observed case, local "ridges" within the pore generated localised stress concentrations leading to a significantly larger concentration factor compared to the other surface pores.

The stress concentration caused by the existence of carbides and pores usually results in enhanced local plastic deformation [23, 24]. In this study, ex-situ SEM-DIC (a surface, inplane technique) was used to investigate the localised strain distribution around the pores and in the matrix. As shown in the literature [32, 34] and our previous study [33], SEM-DIC can capture the strain distribution at the $\mu \mathrm{m}$ scale. In Fig.5, the strain bands locating in the matrix indicate the occurrence of strain localisation and the validity/capability of SEM-DIC to capture the localised strain in this SX superalloy MD2. However, due to insufficient observable natural speckles (i.e. $\gamma^{\prime}$ ) within the pore, and edge effects at the boundaries surrounding the pore, the expected enhanced localised strain distribution was only unambiguously observed in a small region adjacent to the crack-initiated pore which extended sufficiently away from the pore edge (Fig. 6). Further study of localised strain around the pores from the SEM micrographs (Fig. 9) shows a densely populated distribution of dislocations in these regions. In the case of crack initiation within the pore as shown in Figs. 5 and 7, SEM-DIC failed to capture the crack initiation event. In addition, due to the relatively large $\gamma^{\prime}$ (speckles), crack initiation and early stage crack propagation shown in Fig. 
7 cannot be easily detected from the SEM-DIC results as a consequence of the insufficient spatial resolution. Therefore, some artificial speckle such as remodelled nanosized Au particles [34] may provide an alternative solution for the DIC correlation process in these regions. In addition, a future study potentially using stereo SEM-DIC by tilting the surface could aid in detecting local strain accumulation within a pore by considering the local variations in depth, and give further insights into the strain mechanisms leading to the initiation of cracks.

Although SEM-DIC can effectively capture strain localisation at a $\mu \mathrm{m}$ scale with high spatial resolution, the field of view is extremely limited (to ensure the required the spatial resolution) and there is a requirement for small iterative fatigue loading steps and intermittent SEM observations may be required over large areas to ensure the strain accumulation events prior to crack initiation are captured. Being able to better predict where the crack will initiate and at how many cycles is therefore important in being able to fully exploit this full-field technique for relevant regions of interest in the microstructure. The image-based modelling technique demonstrated in this paper has shown that capturing the geometry of the pores and modelling the stress concentrations is important in accurately predicting the location of the crack, and can be linked by reducing the search window for subsequent detailed SEM-DIC work. As a result, this study shows how promising it is to construct a framework for further study of fatigue crack initiation and early propagation mechanisms in SX superalloys from the meso-scale to the micro-scale by combining the full-field techniques of X-ray CT, imagebased modelling and SEM-DIC.

\section{Conclusions}

(1) X-ray CT and SRCT can accurately capture pore and carbide size, morphology and distribution in 3D. The pores and carbides which congregate within the interdendritic regions are dominant fatigue crack initiation sites.

(2) Deformation is concentrated within slip bands at room temperature. Somewhat enhanced strain accumulation around the surface pore is captured by SEM-DIC along with denser dislocation distributions around the pores as characterised by ECCI under controlled diffraction conditions. The crack initiated within the pore was shown to subsequently propagate along the surface strain bands detected by the SEM-DIC analysis. As the crack propagates, strain band density and dislocation density at the crack tip increases correspondingly. 
(3) The stress concentration surrounding the surface pore exacerbates the strain accumulation. Imaged based modelling revealed that the pore which exhibited the greatest stress concentration led to the formation of the crack. The position of the crack initiation observed experimentally correlated with the regions of greatest stress concentrations, which was shown to occur within the depth of the pore at a local "ridge", indicating that the detailed 3D shape of the pore may be critical in determining crack initiating features.

\section{Dataset statement}

The raw data presented in this paper can be found via the DOI http://doi.org/10.5258/SOTON/D048.

\section{Acknowledgement}

The authors would like to thank the MatchID team for provision of the MatchID software. The EPSRC (Grant no: EP/M000710/1) is gratefully acknowledged for funding support. The synchrotron radiation experiments were performed at the BL20XU beamline in SPring-8 with the approval of the Japan Synchrotron Radiation Research Institute (JASRI) (Proposal number 2016A1278). The authors are grateful for the travel funding provided by the Great Britain Sasakawa Foundation and the Global Partnership Award from University of Southampton to visit Spring-8. Dr. A. Harte would like to thank Prof. Stefan Zaefferer at Max-Planck-Institute for Iron Research, Dusseldorf, Germany, for aid in developing the ECCI technique at Manchester and provision of software TOCA. The authors also would like to thank Prof. Liguo Zhao at Loughborough University, Dr. Mark Hardy at Rolls-Royce, Dr. Matthew Lunt at Defence Science and Technology Laboratory, Dr. Gordon McColvin at GE Power, Dr. João Quinta da Fonseca at University of Manchester and Prof. Scott Lockyer at Uniper Technologies Ltd for several useful discussions and comments on the results presented in this paper. Dr. R. Jiang would like to thank Nanjing University of Aeronautics and Astronautics (reference number: 1002-YAH18002) for financial support. Prof. F. Pierron gratefully acknowledges support from the Royal Society and the Wolfson Foundation through a Royal Society Wolfson Research Merit Award.

\section{Reference}

[1] R.C. Reed, T. Tao, N. Warnken, Alloys-By-Design: Application to nickel-based single crystal superalloys, Acta Materialia, 57 (2009) 5898-5913.

[2] R.C. Reed, The Superalloys: Fundamentals and Applications, Cambridge University Press, Cambridge, 2006.

[3] P.A.S. Reed, I. Sinclair, X.D. Wu, Fatigue crack path prediction in UDIMET 720 nickel-based alloy single crystals, Metall and Mat Trans A, 31 109-123. 
[4] K. Prasad, R. Sarkar, K. Gopinath, Role of shrinkage pores, carbides on cyclic deformation behaviour of conventionally cast nickel base superalloy CM247LC® at $870{ }^{\circ} \mathrm{C}$, Materials Science and Engineering: A, 654 (2016) 381-389.

[5] L. Kunz, P. Lukáš, R. Konečná, S. Fintová, Casting defects and high temperature fatigue life of IN 713LC superalloy, International Journal of Fatigue, 41 (2012) 47-51.

[6] T. Link, S. Zabler, A. Epishin, A. Haibel, M. Bansal, X. Thibault, Synchrotron tomography of porosity in single-crystal nickel-base superalloys, Materials Science and Engineering: A, 425 (2006) 47-54.

[7] L.R. Liu, T. Jin, N.R. Zhao, Z.H. Wang, X.F. Sun, H.R. Guan, Z.Q. Hu, Effect of carbon addition on the creep properties in a Ni-based single crystal superalloy, Materials Science and Engineering: A, 385 (2004) 105-112.

[8] L.R. Liu, T. Jin, N.R. Zhao, X.F. Sun, H.R. Guan, Z.Q. Hu, Formation of carbides and their effects on stress rupture of a Ni-base single crystal superalloy, Materials Science and Engineering: A, 361 (2003) 191-197.

[9] X.W. Li, T. Liu, L. Wang, X.G. Liu, L.H. Lou, J. Zhang, Effect of carbon content on the microstructure and creep properties of a 3rd generation single crystal nickel-base superalloy, Materials Science and Engineering: A, 639 (2015) 732-738.

[10] S. Steuer, P. Villechaise, T.M. Pollock, J. Cormier, Benefits of high gradient solidification for creep and low cycle fatigue of AM1 single crystal superalloy, Materials Science and Engineering: A, 645 (2015) 109-115.

[11] M. Guagliano, L. Vergani, M. Šmíd, L. Kunz, P. Hutař, K. Hrbáček, High Cycle Fatigue of Nickel-based Superalloy MAR-M 247 at High Temperatures, Procedia Engineering, 74 (2014) 329332.

[12] L. Rémy, M. Geuffrard, A. Alam, A. Köster, E. Fleury, Effects of microstructure in high temperature fatigue: Lifetime to crack initiation of a single crystal superalloy in high temperature low cycle fatigue, International Journal of Fatigue, 57 (2013) 37-49.

[13] H.U. Hong, B.G. Choi, I.S. Kim, Y.S. Yoo, C.Y. Jo, Characterization of deformation mechanisms during low cycle fatigue of a single crystal nickel-based superalloy, J Mater Sci, 46 (2011) 5245-5251.

[14] P. Lukáš, L. Kunz, M. Svoboda, High-temperature ultra-high cycle fatigue damage of notched single crystal superalloys at high mean stresses, International Journal of Fatigue, 27 (2005) 1535-1540. [15] A. Defresne, L. Remy, Fatigue behaviour of CMSX 2 superalloy [001] single crystals at high temperature I: Low cycle fatigue of notched specimens, Materials Science and Engineering: A, 129 (1990) 45-53.

[16] A. Cervellon, J. Cormier, F. Mauget, Z. Hervier, VHCF life evolution after microstructure degradation of a Ni-based single crystal superalloy, International Journal of Fatigue, 104 (2017) 251262.

[17] J.Z. Yi, C.J. Torbet, Q. Feng, T.M. Pollock, J.W. Jones, Ultrasonic fatigue of a single crystal Nibase superalloy at $1000^{\circ} \mathrm{C}$, Materials Science and Engineering: A, 443 (2007) 142-149.

[18] G.M. Han, Z.X. Zhang, J.G. Li, T. Jin, X.F. Sun, Z.Q. Hu, High cycle fatigue hehavior of a Nickle-based single crystal superalloy DD98M at 900 degrees C, Acta Metallurgica Sinica, 48 (2012) 170-175.

[19] Z. Chu, Y. Jinjiang, S. Xiaofeng, G. Hengrong, H. Zhuangqi, High temperature low cycle fatigue behavior of a directionally solidified Ni-base superalloy DZ951, Materials Science and Engineering: A, 488 (2008) 389-397.

[20] L.Z. He, Q. Zheng, X.F. Sun, H.R. Guan, Z.Q. Hu, A.K. Tieu, C. Lu, H.T. Zhu, High temperature low cycle fatigue behavior of Ni-base superalloy M963, Materials Science and Engineering: A, 402 (2005) 33-41.

[21] R.J. Morrissey, R. John, W. John Porter, Fatigue variability of a single crystal superalloy at elevated temperature, International Journal of Fatigue, 31 (2009) 1758-1763.

[22] I. Serrano-Munoz, J.Y. Buffiere, R. Mokso, C. Verdu, Y. Nadot, Location, location \&size: defects close to surfaces dominate fatigue crack initiation, Sci Rep, 7 (2017) 45239.

[23] L. Wang, N. Limodin, A. El Bartali, J.-F. Witz, R. Seghir, J.-Y. Buffiere, E. Charkaluk, Influence of pores on crack initiation in monotonic tensile and cyclic loadings in lost foam casting A319 alloy by using 3D in-situ analysis, Materials Science and Engineering: A, 673 (2016) 362-372. 
[24] S. Dezecot, V. Maurel, J.-Y. Buffiere, F. Szmytka, A. Koster, 3D characterization and modeling of low cycle fatigue damage mechanisms at high temperature in a cast aluminum alloy, Acta Materialia, 123 (2017) 24-34.

[25] G. Nicoletto, R. Konečná, S. Fintova, Characterization of microshrinkage casting defects of AlSi alloys by X-ray computed tomography and metallography, International Journal of Fatigue, 41 (2012) 39-46.

[26] Z. Yang, J. Kang, D.S. Wilkinson, The Effect of Porosity on Fatigue of Die Cast AM60, Metall and Mat Trans A, 47 (2016) 3464-3472.

[27] Z. Yang, A. Maurey, J. Kang, D.S. Wilkinson, 2D and 3D characterization of pore defects in die cast AM60, Materials Characterization, 114 (2016) 254-262.

[28] P.S. Karamched, A.J. Wilkinson, High resolution electron back-scatter diffraction analysis of thermally and mechanically induced strains near carbide inclusions in a superalloy, Acta Materialia, 59 (2011) 263-272.

[29] M.E. Kartal, R. Kiwanuka, F.P.E. Dunne, Determination of sub-surface stresses at inclusions in single crystal superalloy using HR-EBSD, crystal plasticity and inverse eigenstrain analysis, International Journal of Solids and Structures, 67-68 (2015) 27-39.

[30] T. Zhang, J. Jiang, B.A. Shollock, T.B. Britton, F.P.E. Dunne, Slip localization and fatigue crack nucleation near a non-metallic inclusion in polycrystalline nickel-based superalloy, Materials Science and Engineering: A, 641 (2015) 328-339.

[31] J.C. Stinville, M.P. Echlin, D. Texier, F. Bridier, P. Bocher, T.M. Pollock, Sub-Grain Scale Digital Image Correlation by Electron Microscopy for Polycrystalline Materials during Elastic and Plastic Deformation, Exp Mech, 56 (2015) 197-216.

[32] J.C. Stinville, N. Vanderesse, F. Bridier, P. Bocher, T.M. Pollock, High resolution mapping of strain localization near twin boundaries in a nickel-based superalloy, Acta Materialia, 98 (2015) 29-42. [33] R. Jiang, F. Pierron, S. Octaviani, P.A.S. Reed, Characterisation of strain localisation processes during fatigue crack initiation and early crack propagation by SEM-DIC in an advanced disc alloy, Materials Science and Engineering: A, 699 (2017) 128-144.

[34] F. Di Gioacchino, J. Quinta da Fonseca, Plastic Strain Mapping with Sub-micron Resolution Using Digital Image Correlation, Exp Mech, 53 (2013) 743-754.

[35] F. Borges de Oliveira, A. Stolfi, M. Bartscher, L. De Chiffre, U. Neuschaefer-Rube, Experimental investigation of surface determination process on multi-material components for dimensional computed tomography, Case Studies in Nondestructive Testing and Evaluation, 6 (2016) 93-103.

[36] M. Doube, M.M. Kłosowski, I. Arganda-Carreras, F.P. Cordelières, R.P. Dougherty, J.S. Jackson, B. Schmid, J.R. Hutchinson, S.J. Shefelbine, BoneJ: Free and extensible bone image analysis in ImageJ, Bone, 47 (2010) 1076-1079.

[37] A.D. Kammers, S. Daly, Digital Image Correlation under Scanning Electron Microscopy: Methodology and Validation, Exp Mech, 53 (2013) 1743-1761.

[38] M.A. Sutton, N. Li, D. Garcia, N. Cornille, J.J. Orteu, S.R. McNeill, H.W. Schreier, X. Li, A.P. Reynolds, Scanning Electron Microscopy for Quantitative Small and Large Deformation Measurements Part II: Experimental Validation for Magnifications from 200 to 10,000, Exp Mech, 47 (2007) 789-804.

[39] M.A. Sutton, N. Li, D.C. Joy, A.P. Reynolds, X. Li, Scanning Electron Microscopy for Quantitative Small and Large Deformation Measurements Part I: SEM Imaging at Magnifications from 200 to 10,000, Exp Mech, 47 (2007) 775-787.

[40] ImageJ, http://imagej.net/Image_Stitching.

[41] F. Farukh, L.G. Zhao, N.C. Barnard, M.T. Whittaker, G. McColvin, Computational modelling of full interaction between crystal plasticity and oxygen diffusion at a crack tip, Theoretical and Applied Fracture Mechanics, (2017) https://doi.org/10.1016/j.tafmec.2017.10.010.

[42] S. Zaefferer, New developments of computer-aided crystallographic analysis in transmission electron microscopy, Journal of Applied Crystallography, 33 (2000) 10-25.

[43] S. Zaefferer, Computer-aided crystallographic analysis in the TEM, in: P.W. Hawkes, B. Kazan, T. Mulvey (Eds.) Advances in Imaging and Electron Physics, Elsevier, 2003, pp. 355-XII.

[44] S. Zaefferer, N.-N. Elhami, Theory and application of electron channelling contrast imaging under controlled diffraction conditions, Acta Materialia, 75 (2014) 20-50. 
[45] Q. Yue, L. Liu, W. Yang, T. Huang, J. Zhang, H. Fu, X. Zhao, Influence of withdrawal rate on the porosity in a third-generation Ni-based single crystal superalloy, Progress in Natural Science: Materials International, 27 (2017) 236-243.

[46] M.R. Orlov, Pore formation in single-crystal turbine rotor blades during directional solidification, Russian Metallurgy (Metally), 2008 (2008) 56-60.

[47] L. Qian, X. Cui, S. Liu, M. Chen, P. Ma, H. Xie, F. Zhang, J. Meng, "Image-based numerical simulation of the local cyclic deformation behavior around cast pore in steel, Materials Science and Engineering: A, 678 (2016) 347-354. 